The Geneva Papers on Risk and Insurance, 21 (No. 78, January 1996) 36-49

\title{
The Prudence Concept in EC Insurance Accounts Law
}

\author{
by Hans-Joachim Welzel *
}

\section{Introduction}

Prudence as the counterpart of entrepreneurial risk-taking occupies an equally central role as a business principle as it does in commercial accounting which is subject to uncertainty. The abnegation of artificial "accounting" profits has been a precept for the reputable businessman since time gone by. The prudent determination of assets and results should moreover prevent the emergence of unrealised profits and thus serves to preserve the capital base of the undertaking.

The prudence concept has found expression in numerous accounting regulations, particularly in regulations concerning appropriation accounts and the basis of valuation, and is even emerging in regulations concerning accounts presentation. In view of the complexity of the subject, there is only room here to examine those connections that appear especially significant from the insurance industry's point of view.

The Accounting Guidelines Law of 1985 had established the principle of prudence as the fundamental valuation principle in Germany of both commercial law - before the Commercial Code (CC) was amended in line with EC regulations - also of taxation law, through the principle that the business balance sheet determines the tax balance sheet, in so far as this is not against any tax assessment rules.

\section{Prudence-orientated profit evaluation regulation in the fourth EC Directive (Accounts Directive)}

\subsection{The principle of prudence in the context of General Accounting Principles}

In Article 54, paragraph $3(\mathrm{~g})$, the treaty founding the European Community (EC) gave the relevant EC bodies the responsibility of putting on an equal footing, in so far as was necessary, those protective regulations in Member States relating to companies as defined in Art. 58, para 2 (apart from joint stock companies this also includes mutuals and statutory insurance undertakings) that exist in the interest of shareholders and creditors. A number

\footnotetext{
* Vice Secretary General of the Geneva Association and Deputy General Manager, Gesamtverband der Deutschen Versicherungswirtschaft, Bonn.
} 
of EC guidelines relating to company law were issued as a result of this regulation, including the Fourth Directive, (the "Accounts Directive") and the Seventh Directive, (the "Consolidated Accounts Directive") that are of particular relevance to this subject.

Art. 31, para 1 of the Fourth EC Directive requires Member States to ensure that the items shown in the annual accounts are valued in accordance with the following general principles:

a) the company must be presumed to be carrying on its business as a going concern;

b) the methods of valuation must be applied consistently from one financial year to another;

c) valuation must be made on a prudent basis, and in particular;

aa) only profits made at the balance sheet date may be included,

bb) account must be taken of all foreseeable liabilities and potential losses arising in the course of the financial year concerned or of a previous one, even if such liabilities or losses become apparent only between the date of the balance sheet and the date on which it is drawn up,

cc) account must be taken of all depreciation, whether the result of the financial year is a loss or a profit;

d) account must be taken of income and charges relating to the financial year, irrespective of the date of receipt or payment of such income or charges;

e) the components of asset and liability items must be valued separately;

f) the opening balance sheet for each financial year must correspond to the closing balance sheet for the preceding financial year.

Para 2 permits departures from these principles in exceptional cases. The determination of the basis of evaluation when these general principles are departed from is linked in the interests of transparency to certain disclosure requirements. Any such departures must be disclosed in the notes on the accounts and the reasons for them given; an assessment of their effect on the assets, liabilities, financial position and profit or loss is to be given separately.

With the exception of the principle of consistency of valuation methodology, these general valuation principles were already law in Germany in the form of principles of proper accounting before the implementation of the EC Accounts Directive. The valuation system of German accounts law has therefore not experienced any fundamental change.

These general valuation principles from the Fourth EC Directive were put into effect by Article 252 of the Commercial Code. In the process explicit incorporation of Art. 31 para 1 (c) (cc) - in which account must be taken of all depreciation, regardless of whether the result of the financial year is a profit or a loss ("write-down" principle) - was dispensed with, as the principle it contained "goes without saying" as far as the German legislators were concerned.

The general valuation principles of Art. 252 of the Commercial Code are clearly defined by special valuation regulations as a "lex specialis", for example valuation according to the acquisition cost or lowest values principles, but are also qualified by options in the areas of application and valuation, to which we return to in greater detail below. 


\subsubsection{Systematic categorization of the principle of prudence}

Due to the lack of any defined order of importance, the valuation principles are stated in the literature to be "of equal importance and fundamentally independent of each other".

All the valuation principles cited in Art. 3. of the Fourth Directive can be seen to have been influenced by the principle of prudence.

The applicable principle of prudence (as defined in Art. 31 para 1 (c) and Art. 252 para 1 (4) of the Commercial Code, as well as having regard to the special valuation regulations) is also acknowledged by prevailing opinion as a "general maxim", from which a number of further valuation principles can be derived. In addition the prudence principle had also influenced a number of particular regulations in the EC Accounts Directive, such as the regulation that creditors and debtors must be shown separately for associated companies or companies in which there is a holding relationship (Art. 9, Fourth Directive) or the regulation that contingent liabilities must be disclosed under the balance sheet or in the appendix (Art. 14, Fourth Directive).

\subsubsection{Characteristics of the principle of prudence}

One must first refer to the principle of anticipation of losses and to the principle of realisation of profits. As parts of the requirement for prudent valuation, they have been defined as follows in Art. 252 of the Commercial Code:

- all foreseeable liabilities and potential losses arising up to the balance sheet date are to be taken into account, even if such liabilities or losses become apparent only between the date of the balance sheet and the date on which it is drawn up;

- only profits made at the balance sheet date may be included.

According to the prevailing view of the hierarchy of general valuation principles, the acquisition cost principle derives from the principle of realisation of profits, whereby assets may at most be recorded in the balance sheet at acquisition or production cost, as the assignment of any higher value would automatically result in the inclusion of unrealised gains.

In contrast to the realisation of profits principle, the related principle of the anticipation of losses is a requirement to anticipate foreseeable liabilities and potential losses at the balance sheet date. From this the lowest value principle - and highest value for liabilities - as well as the creation of provisions for pending losses from unexpired business can be derived.

Closely connected with the principle of prudence, and the anticipation of losses and realisation of profits principles derived therefrom, is the principle of itemized valuation of assets and liabilities, in which provisions are also to be included. This principle, enshrined in Art. 252, para 1 (3) of the Commercial Code, states that items forming part of a total are to be noted and valued individually and the value of the total is to be determined from the sum of the individual items.

According to Perlet, the chief significance of the itemized valuation principle is "to prevent the reduction of the total liabilities. The principle of anticipation of losses should not be undermined by unrealised gains in the value of existing assets being included indirectly by balancing them against unrealised losses in an overall valuation".

The principle of prudence is further to be found in regulations that "serve to restrict the assets side of the balance sheet and thus prevent "non-values" from being included". The consequences for the liabilities side that relate specifically to insurance will be discussed later on. 
The presumption that business is being carried on as a going concern, in so far as this does not come into conflict with any factual or legal realities, also relates to the principle of prudence to the extent that it ensures the balance sheet is drawn up with this principle in mind and therefore that no liquidation values in excess of the acquisition values are included.

The principle of disclosure also derives from the principle of prudence, as items of information received between the date of the balance sheet and the date on which it is drawn up must also be incorporated in a prudent manner.

The prudence concept has not only determined which principles are to be used for drawing up a balance sheet, but is also of significance for the valuation process itself. More exactly, prudent valuation is "to be understood as a valuation rule to be applied everywhere where due to incomplete information or uncertainty about future events a range of possible values inevitably exists".

\subsection{The principle of prudence in the regulations concerning the presentation of accounts and valuation.}

\subsubsection{Prohibitions and options in respect of assets}

Not least due to the German influence on the Fourth Directive, the harmonised accounts law, resulting from the EC Accounts Directive, contains numerous prudence based prohibitions of certain assets in the balance sheet and also presentation and valuation options. Adler/Düring/Schmaltz have listed these in relation to German commercial law: balance sheet exclusions (Art. 248), asset options (Art. 250, para 1 (2) and para 3; Art. 255, para 4; Arts. 269, 274 (para 2), liability options (Art. 249, para 1 (3) and para 2, writing down options (Art. 253, para 2 (3), para 3 (3) and para 4), retention of value options (Art. 253, para 5), options for the inclusion of fixed costs in the costs of production (Art. 255, para 2 (3) \& (4)), and inclusion prohibitions (Art. 255, para 2 (6) and para 3 (1). The options also follow on from the prudence concept, as they should ensure that assets and profits are shown on a more conservative basis for reasons of prudence.

\subsubsection{Modified and strict lowest value principle in the context of acquisition cost valuation}

It is with the acquisition cost principle - and the traditional derivations therefore that are to be found in German Accounts law, the modified lowest value principle (Art. 35 of the EC Accounts Directive) and the strict lowest value principle (Art. 39 of the EC Accounts Directive) - that the principle of prudence has had the most significant impact on European Accounts law. In accordance with the principle of realisation of profits, gains in value of the existing assets in excess of the acquisition or production costs are not included when calculating profit. However, in accordance with the principle of anticipation of losses, unrealised losses are included in the calculation.

The modified lowest value principle applicable to permanent investments (that are designated as being permanently employed in the business) only requires depreciation to be considered on the basis of the principle of anticipation of losses, if depreciation is expected to be permanent. On the other hand, the strict lowest value principle applicable to traded investments requires the use of a lower value - resulting from the stock market or the market price at the balance sheet or the value that has to be ascribed thereto-even when depreciation is possibly only of a temporary nature.

The unrestricted retention option of earlier German company law, whereby lower valuations made in this way could be retained even after subsequent increases in value (see 
Art. 154, para 2 (2) and Art. 155, para 4 of the Company Law "65) has been completely withdrawn (see Art. 35, para 1 (c) (dd) in respect of permanent investments and Art. 39, para 1 (d) of the Fourth Directive in respect of traded investments) to prevent hidden reserves from being intentionally formed. However by virtue of the contrary principle that the business accounts determine the assessment of tax, this additional safeguard remains available to German joint stock companies in practice (see Art. 280, para 2 of the Commercial Code).

The difference in stringency of the writing down requirement as between the modified and strict lowest values principles is justified by the functional differences between the two types of asset - permanent investments and traded investments. Whereas a reduction in value of permanent investments (i.e. designated as being permanently employed in the business) that would appear to be of a temporary nature may be disregarded from the point of prudent assessment of profit, commercial accounting law does not allow the same to apply to what a reasonable business assessment would also perceive as a short term change in the market value of traded investments.

\subsubsection{Art. 33 of the Fourth Directive - exception from the acquisition cost principle and equivalent principles}

The most controversial regulation in the Fourth Directive is the exception from the Acquisition Cost principle allowed for in Art. 33. This was included in the Directive at the insistence of the UK and, after a conflict of views, particularly with the Federal Republic of Germany, a compromise was formulated at the time to prevent the Fourth Directive from breaking down.

However it appears that those concerned were thoroughly aware of the problems ensuing from a derogation from that close relative of the principle of prudence, the acquisition cost principle. Thus

- the regulation is subject to the possibility of general revision ("until a later coordination"),

- Art. 33, para 5 of the Fourth Directive provides for a special examination and, if necessary, amendment of Art. 33 in the light of the community's economic and monetary development,

- the authorised divergences from the acquisition cost valuation are restricted in respect of valuation methods and, in part, the type of assets involved,

- the principle of itemized valuation and the lowest value principle also apply when a valuation method according with Art. 33 of the Fourth Directive is used

and, in particular,

- unrealised gains arising from the use of these valuation methods as opposed to a valuation on an acquisition cost basis are to be held in a special (revaluation reserve) and are excluded from any form of distribution until such time as they may be realised.

Thus, in regard to preservation of capital one sees an equivalent to the prudence orientated principle of acquisition cost valuation. 


\section{Prudence orientated profit evaluation regulations in the EC Directive on the Accounts of Insurance Undertakings (EC - IAD)}

\subsection{Fundamental principles}

\subsubsection{The EC Accounts Directives}

Like the EC Banking Accounts Directive, the Directive on the Accounts of Insurance Undertakings (IAD) is not a normative work, independent of the Fourth and Seventh EC Directives. Instead both directives bring to completion the accounting regulations, whose coordination had already been foreseen in Art. 1, para 2 of the Fourth Directive and Art. 40 , para 1 of the Seventh Directive. They are solely concerned with those particular areas relating specifically to banks and other financial institutions and to insurance undertakings. They therefore only regulate divergences from the Fourth and Seventh EC Directives (cf. the considerations precedent to the Banking Accounts Directive and the IAD).

In contrast to the Fourth and Seventh company law Directives, the regulations in the IAD are not just restricted to controlling the operations of joint stock companies, but, in the interests of equal competition within the European internal market, the Directive includes all authorised forms of insurance undertakings, including mutuals and statutory insurance undertakings.

\subsubsection{Pluralism of valuation methods - Departure from the primacy of the acquisition cost principle}

The most spectacular single aspect of the EC guideline is the departure from the primacy of the acquisition cost principle in the valuation of assets. Right from the start, twelve years ago, the intention was to give parity of treatment to the acquisition cost and current value methods (Art. 46, para 1). Valuation on the current value basis can be permitted or required by Member States, either in relation to all investments or to individual sub-items within Item C - "Investments" - of the balance sheet.

This does not however apply to "investments for the benefit of Life Assurance Policyholders who bear the investment risk" (Asset Item D), i.e. in particular investments relating to "unit-linked life assurance", comparatively large amounts of which are written in the UK; these investments must be valued at current value per Art. 46, para 2 IAD.

Art. 55 permits debt securities and other fixed interest securities to be valued in a special way:

The Member States can permit or require that these securities be shown in the balance sheet at the amount repayable at maturity and that the difference between this value and the respective purchase price be amortized over the period remaining until maturity.

This method, which is also found in the Banking Accounts Directive, is clearly intended to ensure, in the interest of comparability between accounting periods, a continuous release of investment earnings, by allowing an anticipated but even return on investment. The same consideration also applies to other fixed interest investments with premiums/discounts such as mortgages and loans against promissory notes.

In addition to current value valuation, there is one further important and widely applicable exception: Member States can permit or require revaluation in the sense of Art. 33, para 1 (c) of the Fourth Directive (see also Articles 44 and 50 IAD). This significantly 
broadens the range of methods which may be used to value investments, but without requiring that the comparability with the other two basic valuation methods be disclosed in the notes to the accounts.

We shall return to the treatment of the resulting unrealized gains arising from the use of these valuation methods that depart from the Acquisition Cost valuation principle.

\subsubsection{Special valuation options}

The legal structure is not yet sufficiently defined with regard to this fundamental departure from the Fourth Directive's valuation system. The Member State options relating to balance sheet preparation and to valuation that are set out below create considerable latitude for the calculation of the profits of insurance undertakings. According to the option chosen, there can be considerable timing differences in the amount of profit shown. The heterogeneous nature of the IAD's valuation methodology - one could say inconsistency becomes fully clear when one considers that the initially described prudence-based valuation principles initially established in the Fourth Directive also apply to insurance undertakings. Special reporting conditions exist to help overcome the differential observance of the prudence principle.

This applies to the following Member State options:

- Art. 18: Deferral of acquisition costs through inclusion as an asset or by deduction from technical provisions (provision for unearned premiums, actuarial reserves) or their immediate write-off as an expense.

- Art. 51: Strict lowest value principle for securities.

- Art. 60: Discounting of the claims provision where the average date of settlement is over four years.

- Art. 62: "Pending further coordination, those Member States which require the constitution of equalization provisions shall prescribe the valuation rules to be applied to them."

At their most extreme, the contrasting options might be:

- on the one hand, current values with deferred acquisition costs and discounted claims provision and

- on the other hand, valuation by the purchase cost principle without deferred acquisition costs and without discounted claims provision.

However, these extreme examples, which do not represent the whole range of possible variations, are probably less likely to be used in practice by the EC Member State than a mixture of methods.

The most significant variations between these diverse "optimistic/pessimistic" models relates to timing differences in the impact on the result, i.e. the declaration of profit. Apart from the interest and tax implications, the end effect is the same.

\subsection{Prudence in the balance sheet and valuation regulations of the IAD}

\subsubsection{Treatment of intangible assets}

In this connection there are three business areas that can be of considerable importance for insurance undertakings:

- Expenses relating to the establishment or expansion of the undertaking.

- Payment for the value of a business or company.

- Insurance policy acquisition expenses. 
It is worth noting here that Member State options exist in all three areas. This creates the possibility of maintaining the status quo in harmonising national law with the IAD. German legislators have recognised this possibility by confirming in Art. 341 (a), para 1 of the Commercial Code that Art. 269 and Art. 255, para 4 of the Commercial Code continue to apply also to insurance undertakings; furthermore the current regulation from Art. 56, para 2 of the Insurance Supervision Law has been incorporated in Art. 248, para 3 of the Commercial Code. At the same time, in view of the Insurance Accounts Directive's goal of common accounting standards for all types of undertaking, mutual insurance undertakings have put on an equal footing with other types of undertaking in the way in which business establishment or expansion expenses are treated (Application of Articles 269 and 282 of the Commercial Code and rescinding of Art. 36a of the Insurance Supervision Law).

The question of how deferred acquisition costs are to be included in the balance sheet is of particular importance as contracts lasting several years are common in Germany - in contrast to most EC Member States. German legislators have decided to retain the prohibition on the inclusion of deferred acquisition costs in the balance sheet (per Art. 56, para 2 of the Insurance Companies Law), by adopting the regulation from the Insurance Supervision Law in Art. 248, para 3 of the Commercial Code. A telling example of the comparatively "looser" balance sheet accounting concepts of the IAD is that in principle deferred acquisition costs are required to be shown as assets, whereby reference is made to the regulations governing apportionment in Art. 18 of the Fourth Directive.

This does not affect the question of Zillmerization; according to current German law this is not an apportionment of expenses but of recognition in the balance sheet of an insurance undertaking's entitlement (substantiated by the business plan) to write off deferred acquisition costs.

The risk of loss is met by an overall adjustment or a so-called cancellation provision.

\subsubsection{Valuation of investments}

\subsubsection{Valuation methods}

Three basic valuation systems, offering a number of valuation methods, are available to Member States at their option. The only exception to this is the valuation of "investments for the benefit of Life Assurance Policyholders who bear the investment risk", i.e. particularly investments of unit-linked life business, which in future will have to be valued on the basis of current value alone. The three available systems are:

- Valuation according to the acquisition cost principle as per Art. 32 of the Fourth Directive (Art. 45).

- Valuation according to the current value principle as per Art. 48, 49 of the IAD (Art. 46).

- Revaluation as per Art. 33, para 1 (1) (c) of the Fourth Directive (Art. 50).

When opting for the acquisition cost principle, the modified lowest value principle on the basis of Art. 51 applies. Member States can, however, require the application of the strict lowest value principle where securities are shown separately from other investments. Thus in the area of investments the German legislators have taken advantage of this possibility in Art. 341 (b), para 2 (1) of the Commercial Code in order to maintain the status quo. At present the investments of insurance undertakings are valued according to the modified lowest value principle, with the exception of transferable bearer securities, which are to be 
valued by the strict lowest value principle in accordance with Art. 56, para 1 of the Insurance Supervision Law. In this respect the Accounts Directive also retains the existing legal basis applicable to those permanent investments that are (as legally defined) designated to support the business as well as those assets that are to be valued as investments.

Member States can permit a nominal valuation, with pro-rata write-off of premiums or discounts, of debt securities and other fixed interest securities which are not considered to be liquid reserves and are therefore not required to be valued according to the strict lowest value principle. As long-term investments, the ability of these securities to cover debts at the given value is not put into question.

One should not overlook the fact that, depending on the level of interest rates, a valuation on the basis of the modified lowest value principle can produce higher values in the balance sheet than would be admissible according to the current value principle. In future, however, this difference in values will be shown in the notes concerning the disclosure of the current value of investments. This will enable the reader of the balance sheet to see for himself in quantitative terms the actual effect of the two different valuation methods.

On the other hand, the authorized application of strict lowest value valuation - still a requirement in Germany - to those transferable securities serving as liquid reserves can inherently never produce higher values than current value valuation, but only lower ones. On the one hand, this is due to the acquisition cost related upper value limit of the lowest value principle, on the other due to the retention option, that in future will be effective in Germany as a result only of the decision to the contrary.

The EC Insurance Accounts Directive gives current value valuation and revaluation (per Art. 33 of the Fourth Directive) as further valuation alternatives. These are defined in Articles 48 and 49 of EC IAD and Art. 33 of the Fourth EC Directive.

Here it should be noted that the EC-IAD's definition of current value is relatively differentiated and designed to suit the different investment categories. With the exception of land and buildings, and participations in affiliated companies that are to be valued by the equity method, a basis of valuation is to be prescribed which, in accordance with Art. 48, para 5, "takes account of the foreseeable realisation value and the principle of prudence".

By contrast, Art. 33 of the Fourth Directive leaves open what is to be understood by revaluation; though in the meantime practical experience should be available. Conceptually both methods must use different valuation approaches, although revaluation (per Art. 33 of the Fourth Directive) should be aimed at registering "increases in value that have a permanent trend" and neutralizing them with a revaluation reserve.

\subsubsection{Treatment of unrealized gains}

Both valuation methods have in common that in their application they show unrealized gains, where values exceed the acquisition cost. This contradicts the prudence and realization principles and for this reason neither of these two valuation options came under consideration for inclusion in German commercial accounts legislation.

A neutralization of these book profits by their obligatory inclusion in a special reserve that may only be distributed according to the realization of the profit (as is required by Art. 33 of the Fourth Directive) would here represent an equivalent. The IAD regulations relating to this are of crucial significance from the prudence point of view. In my opinion, however, they are complicated and questionable. 
For unrealized gains and losses arising from the current value method, Art. 44 IAD states:

(1) In Life assurance business Member States may permit variations in the difference between

- the valuation of investments at their current value or by means of one of the methods referred to in Art. 33, para 1 (!) of the Fourth Directive and

- their valuation at acquisition cost

to be disclosed in full or in part under items II (3) and (10) (Unrealized gains on investments/unrealized losses on investments) in the Profit and Loss Account.

In any event, Member States shall require that the amounts referred to in paragraph 1 be disclosed in the aforementioned items where they relate to investments shown as assets under D, i.e. investments for the benefit of Life Assurance Policyholders who bear the investment risk.

(2) In non-life insurance, Member States which require or permit the valuation of the investments shown as assets under $\mathrm{C}$ at their current value may permit the inclusion of changes in the difference between the valuation of those investments at their current value and their valuation at acquisition cost in the profit and loss account in full or in part in a (special) item III (3a) or item III (5a).

Thus disclosure under the items "Unrealized gains on investments" and Unrealized losses on investments" is only mandatory in relation to gains and losses from investments for the benefit of Life Assurance Policyholders who bear the investment risk. In other cases it is dependent on an undertaking exercising an option that Member States can permit.

What happens when a Member State does not permit the disclosure in the profit and loss account? In this case the method set out in Art. 33 of the Fourth Directive applies, i.e. the setting up of a revaluation provision with the respective possibilities and conditions (Art. 47 IAD) but possibly without impact on the profit and loss account.

If a revaluation of investments according to Art. 33, para 1 (c) of the Fourth Directive is made, the legal provisions which apply are those of the Fourth Directive; however, these provisions do not require the disclosure of the amounts written up in the profit and loss account. One might consider a neutralization outside the profit and loss account through the formation of a revaluation reserve which, again, may be transformed into subscribed capital, i.e. free assets (!).

An exception to the neutralization of gains resulting from revaluations, which is required by Art. 33 of the Fourth Directive, is permitted by Art. 44 of the IAD in respect of life assurance. According to this, Member States may permit the differences in value resulting from the application of one of the valuation methods of Art. 33, para 1 of the Fourth Directive to be disclosed in the results as unrealized gains or losses.

The extension of the regulation on neutralization of Art. 33, para 2 of the Fourth Directive to gains resulting from revaluation with regard to all investments - according to Art. 33, para 1 , sentence 1 (c) of the Fourth Directive a revaluation is only admissible with regard to tangible and financial assets - and the application of this procedure to the valuation at current value, which is also applicable to all investments, is questionable because of the transformation of volatile asset values into subscribed capital, which would be possible in this case. 
However, in my opinion, it is even more questionable that the system obviously makes it also possible to distribute unrealized gains arising from the current values, albeit with a delay in the event that, in accordance with Art. 22 of the IAD, they are included in the fund for future appropriations, "where a Member State permits an undertaking's balance sheet to include funds the allocation of which either to policyholders ot to shareholders has not been determined by the close of the financial year"; however this appears in practice only to concern life assurance.

\subsubsection{Setting-up and calculation of technical insurance provisions}

\subsubsection{Fundamental principles}

In addition to the valuation principles of Art. 31 of the Fourth Directive (described above), the general norm in Art. 56 of the IAD applies to technical insurance provisions. This requires that technical provisions should at all times ensure that the insurance undertaking can fulfil all its obligations arising from insurance contracts, in so far as these obligations are reasonably foreseeable.

According to the pronouncements of the EC Council and Commission, the amount of the provisions required by Art. 56 corresponds to the amount seen in Germany as enabling an undertaking using sensible business judgement to meet its insurance policy obligations in the long term.

By means of Member State options and latitude in methods of calculation, the IAD allows a wide valuation range within the current German law and the concept of prudent profit evaluation based on the fundamental principle of realisation of profits. The extent of this range can be illustrated by the example of the regulations concerning:

- Claims provisions

- Provisions for possible losses from pending business

- Fluctuation Provisions and Provisions for Large Risks

The effects on the liabilities side of the balance sheet will differ considerably according to the option chosen. In contrast to the valuation differences arising from the various permitted methods of investment valuation, there are no neutralization mechanisms here to prevent a distribution of profits on the basis of the realisation of profits principle which would thereby lessen the consequences that result from this variety of valuation methods for the profitability of insurance undertakings in the common European market. Additional requirements for disclosure of information, included by the IAD in the interests of comparability between different valuation methods, are a poor substitute.

\subsubsection{Safeguards and relaxations for claims provisions}

The regulations for outstanding claims provisions in Art. 60 concerning general insurance business contain a number of "classic" safeguards in line with the prudence principle of the Fourth Directive:

- The fundamental idea of itemized valuation is specifically stressed; statistical methods are permitted if they create an adequate provision having regard to the nature of the risks involved.

- The provision is "to be created to meet the amount of the expected outstanding payments", i.e. the amount corresponding to the estimated settlement amount.

- An IBNR claims reserve is to be set up for claims incurred up to the date of the balance sheet, but not yet reported. This prevents the balance sheet from showing insufficient provision for liabilities and the distribution of unrealized profits. 
- Claims settlements costs "of whatever nature" are to be included in the calculation of the claims provision; the exclusion of claims administration expenses from the reserve does not therefore appear to be justified.

- Recoverable amounts deriving from subrogation and salvage that can be deducted from the claims provisions are to be assessed according to the principle of prudence.

- Hidden discounts, for instance where insurance payments are shown as an amount lower than the expected final settlement, are inadmissible.

- In contrast to these safeguards which serve the principles of prudence and realisation of profits, the (Member States) option of explicit discounting is a relaxation and a sin against the spirit of the principle of realisation of profits, notwithstanding that such discounting is subject to certain limitations and that its effect on the results must be disclosed in the notes on the accounts. To this extent the IAD permits insurance undertakings to calculate provisions at a level below the Fourth Directive's safety standards applicable to other business areas.

\subsubsection{Valuation components and parameters for provision for pending losses}

In contrast to current German law, the IAD contains insurance-specific regulations concerning the provision for pending losses in insurance business (Article 26 and 58). The provision for pending losses is defined as a provision in Art. 20 of the Fourth Directive and according to Art. 26 of the IAD represents "the amount set aside in addition to unearned premiums in respect of risks to be borne by the insurance undertaking after the end of the financial year, in order to provide for all claims and expenses in connection with insurance contracts in force in excess of the related unearned premiums and any premiums receivable on those contracts".

The loss in respect of pending business is the value of the insurer's excess of liability for future claims over the expected future premiums.

In terms of the results, acquisition expenses are excluded (Articles 26 and 58 of the IAD) - regardless of their inclusion in the balance sheet (!). The question of whether interest income should be included in the evaluation of pending losses remains open, as does the question regarding the inclusion of changes in any fluctuation provisions.

The IAD contains no regulations on the question of discounting of the component parts of the provision for pending losses - such discounting should be rejected on grounds of considerations relating to the principles of realisation of profit and anticipation of losses, similar to those relating to claims provisions. Similarly, the IAD contains no regulations concerning two such important valuation parameters as the delay period of loss settlement and the grouping on which the loss calculation should be based.

Whilst Laaß interprets the text to mean that the outstanding period to be applied in the calculation of the provision extends to the point in time when the next annual premium is due, Geib/Ellenbürger/Kölschbach - in line with the general opinion - settle for the effective remaining period, in evaluating the average period of delayed payments.

With regard to the question of grouping, the principle of itemized valuation fundamentally applies to the provision for pending losses as well. The collective basis of calculation and risk equalization in insurance requires a proper interpretation of this prudence-based principle; the examination of individual policies without considering the group as a whole would be as inappropriate as an overall examination of the whole portfolio. 
Although Karten consistently uses policy-based estimates for claims and expenses in his proposal, he also determines them from grouped statistics.

The determination of the proper grouping would be the crucial question here.

If one agrees with Geib/Horbach and Ziegler that the condition for this is equal calculation of policies, then one arrives at relatively differentiated calculation groupings. From a practical point of view grouped averages can also be considered as is the case with the Equalization Provision Regulation, which would also make it easier to take the equalization provision into account in this calculation.

However, I consider that reference to the total portfolio is not in accordance with the prudence related principles of realisation of profits and anticipation of losses, as this would entail future profits being used to compensate for expected losses as a result of the equalization inherent in the grouping. It is to be hoped that acceptable standards will develop in this area at a European level.

\subsubsection{Application options for equalization provisions and provisions for large risks}

The IAD does not provide for a separate obligation to create equalization provisions and provisions for large risks. The First Non-Life Directive does, however, stipulate the creation of a provision for credit insurance, applicable throughout the EC. Art. 30 of the IAD simply requires that amounts set aside in compliance with (national) legal or administrative requirements are to be shown as technical provisions and that those provisions constituted to equalize fluctuations in loss ratios in the absence of any such (national) requirements are to be disclosed in the notes on the accounts.

Thus it is not only the case that - with the exception of Credit insurance - there is a Member State option for the requirement to create a fluctuation provision and the "similar" provision for large risks, but that even for credit insurance, EC law allows a choice between two different basic approaches. Alongside two variants that correspond to the "German model" (that aims to equalize the claims ratios), two other variants (that aim to equalize technical losses) are equally available to choose from, although it would be reasonable to express doubts as to their equal value from the security and equalization points of view.

Referring to current German regulations, Karten has impressively set out the equalization provision's role in the context of prudent accounting for an insurance undertaking:

"Following on from the prudence principle(emphasised by the author) as the corner stone of proper accounting, a static approach would see the evaluation of future liabilities arising in a given portfolio - either as a positive or negative difference - as leading to the formation of a provision, in accordance with the principle of anticipation of losses. The size of the provision would be determined on the basis of a prudently determined probability that it would not be exceeded by the cumulative claims deficiencies and surpluses. Such a static based reserve for uncertain liabilities - that could also be interpreted as an extended pending loss provision - would, however, be inflexible and unsuited to fulfil its equalization function.

On the other hand, the application of the principle of realisation of profits to the workings of the risk business offers a sound, dynamically orientated foundation for a flexible provision in its own right. Only if such a fluctuation provision - that in principle corresponds to the model's reserving process - has reached an upper limit declared as being adequately safe, can surpluses over and above this limit be deemed realised and distributable profits. In the end effect the result essentially corresponds to the equalization provision after 1978." 
It is to be hoped that this understanding of the demands made on the insurance business by the principle of prudence in the interests of the security of the undertaking and the continuing ability of insurance policies to fulfil their obligations will soon be held in common throughout Europe.

\section{Conclusion}

To summarise, it can be concluded that although the IAD is based on the prudence oriented general accounting principles of the Fourth Directive, considerable latitude is, however, provided by a number of Member State options concerning application and valuation. Some of the applications permitted do not in fact match up to the Fourth Directive's security requirements.

In particular this applies to revaluation (in accordance with Art. 33 of the Fourth Directive), current value valuation of investments without a distribution bar and application and valuation options concerning technical provisions.

That the Member State options make it possible to fall short of the Fourth Directive's security standard is even less understandable when one considers that the credit industry which has to meet similarly high standards of confidence as the insurance industry - was only allowed to take the route of greater prudence in accounting standards when exercising Member State options to deviate from the Fourth Directive's level of prudence.

In the interests of the insurance industry's credibility in the European internal market, it is to be hoped that Member States will exercise in a prudent manner the options that they have been granted. 